\title{
Recommendations for followup of stage I and II seminoma: The Princess Margaret Cancer Centre approach
}

Hester Lieng ${ }^{1}$; Padraig Warde ${ }^{1}$; Philippe Bedard ${ }^{2}$; Robert J. Hamilton ${ }^{3}$; Aaron R. Hansen ${ }^{4}$; Michael A. S. Jewett ${ }^{3}$; Martin O'Malley ${ }^{4}$; Joan Sweet ${ }^{5}$; Peter Chung ${ }^{1}$

${ }^{1}$ Radiation Medicine Program, Princess Margaret Cancer Centre, University Health Network and Department of Radiation Oncology, University of Toronto; ${ }^{2}$ Division of Medical Oncology \& Hematology, Princess Margaret Cancer Centre, University Health Network and Department of Medicine, University of Toronto; ${ }^{3}$ Department of Surgery (Urology) and Surgical Oncology, Princess Margaret Cancer Centre, University Health Network, University of Toronto; Division of Medical Oncology \& Hematology, Princess Margaret Cancer Centre, University Health Network and Department of Medicine, University of Toronto; ${ }^{4}$ Division of Abdominal Imaging, Joint Department of Medical Imaging, University of Toronto; ${ }^{5}$ Department of Pathology and Lab Medicine, University Health Network, University of Toronto; Toronto, ON, Canada

Cite as: Can Urol Assoc J 2017 Dec. 1; Epub ahead of print. http://dx.doi.org/10.5489/cuaj.4531

Published online December 1, 2017

$* * *$

\section{Abstract}

Testicular seminoma most commonly affects young men and is associated with favourable prognosis. Various followup schedules and imaging protocols for testicular seminoma have been described without overall consensus. We reviewed the literature together with our experience at the Princess Margaret Cancer Centre and present an evidence-based followup approach for patients with stage I and II seminoma.

\section{Introduction}

Testicular seminoma accounts for less than $1 \%$ of malignancies, with median age at diagnosis of $30-40$ years. ${ }^{1}$ Early stage (stage I and IIA/B) testicular seminoma has 5-year overall and disease-specific survival rates that exceed $90 \%$ and 95\%, respectively. ${ }^{2-9}$ Published guidelines for testicular seminoma provide consistent treatment recommendations, but followup schedules vary. ${ }^{10-14}$ The aim of followup after cancer treatment is to detect and manage relapse, but monitoring and treating toxicity from therapy is also necessary. We reviewed the literature and the Princess Margaret Cancer Centre experience regarding followup of stage I and II testicular seminoma and make recommendations for an evidencebased followup approach.

\section{Stage I seminoma}

After radical orchiectomy for stage I seminoma, management options include active surveillance, adjuvant radiotherapy, or adjuvant carboplatin. As relapse rates and patterns of failure differ with each treatment, a tailored followup program is needed. 


\section{Surveillance}

The risk of relapse after radical inguinal orchiectomy alone is estimated to be $13-20 \%$ at 5 years, ${ }^{15-18}$ but long-term cure rates approach $100 \% .{ }^{19-21}$ At the Princess Margaret Cancer Centre, all men with stage I seminoma are advised of treatment options and recommended surveillance.

Each followup visit includes a history and physical examination. In the first 3 years, 6-monthly low-dose computed tomography (CT) scans of the abdomen and pelvis are performed. Thereafter, CT scans are limited to the abdomen only and performed every 1-2 years as outlined in Table 1. Serum hormone levels (total testosterone, luteinizing hormone $[\mathrm{LH}]$ and follicle stimulating hormone $[\mathrm{FSH}]$ ) are measured annually, but serum tumor markers have been eliminated.

\section{History and physical examination}

Physical examination to detect disease recurrence is of limited value, but should include examination of the scrotum, contralateral testis, and lymph node regions, particularly the inguinal and supraclavicular sites. A Danish study reported 5\% of the 353 relapses were found by physical alone, ${ }^{9}$ and in a pooled series of more than 1300 men, physical examination did not identify any relapses. ${ }^{16}$ Isolated inguinal lymphadenopathy found by physical examination are usually associated with previous surgery and altered lymphatic drainage. ${ }^{22}$ In our series of 766 surveillance patients, there were 2 cases of biopsy-confirmed inguinal lymphadenopathy. ${ }^{23}$ Metachronous contralateral testicular tumors occur in $1-2 \%$ of men with testicular seminoma. ${ }^{24,25}$

At the Princess Margaret Cancer Centre, total testosterone, LH, FSH levels are measured annually. A population-based study of testicular cancer survivors found these men were at greater risk of low testosterone and high FSH and LH levels over time compared to healthy controls. ${ }^{26}$ Hypogonadal symptoms associated with consistently low testosterone levels may be managed with testosterone replacement and referral to endocrinology. ${ }^{27}$ A brief psychosocial review is performed to screen for underlying anxiety and depression. ${ }^{28}$, ${ }^{29}$ Men with testicular cancer may have increased rates of anxiety and suicide compared to the general population. ${ }^{30,31}$ We recommend the validated Patient Health Questionnaire-9 (PHQ9) and Generalized Anxiety Disorder 7-item scale (GAD-7) as screening tools, and at our institution, these are combined with other standardized validates measures of distress, and completed by patients prior to clinical review. Depending on their screened level of distress, interventions range from providing information on supportive services to referral to a specialist psychologist or psychiatrist for further assessment and management.

\section{Imaging}

\section{Computed tomography (CT)}

Men on surveillance are most likely to relapse in the retroperitoneum. ${ }^{9,15,23,32}$ At the Princess Margaret Cancer Centre, ${ }^{23}$ similar to the Danish cohort study, ${ }^{9}$ retroperitoneal metastases either in isolation or with synchronous pelvic or inguinal metastases, accounted for $93 \%$ of relapses. Abdominopelvic CT is the main method of detecting infradiaphragmatic relapses in $85-99 \%$ of surveillance cases. ${ }^{\text {9, 16, } 23}$ 
Given the duration of followup and frequency of imaging, radiation-induced malignancy is a concern in these young men. A single abdominopelvic CT scan is estimated to expose patients to $10-20 \mathrm{mSV}$ of radiation, ${ }^{33,34}$ with the Biological Effects of Ionizing Radiation (BEIR) VII phase 2 report estimating a 1 in 1000 risk of a radiation-induced cancer from 10 mSV based on epidemiologic studies. ${ }^{35}$ To minimize this risk, less frequent CT imaging, as well as the use of low-dose CT or MRI have been described. ${ }^{19,36,37}$ A study of low-dose CT with model-based iterative reconstruction during followup of early stage testicular germ cell tumors, demonstrated comparable or superior image quality and a reduction in radiation dose by $67 \%$, compared to conventional dose imaging. ${ }^{36}$ Our prospective phase 2 study of lowdose abdomen/pelvis CT during surveillance for stage I germ cell tumors found that although the diagnostic quality of low-dose CT was slightly inferior to standard-dose CT, image quality was acceptable in $99 \%$ of cases with no false negative readings, and resulted in a median dose reduction of 55\% compared to standard-dose CT. ${ }^{37}$ At the Princess Margaret Cancer Centre since 2012, all abdominopelvic CT imaging during followup of testicular germ cell tumors utilize this same low-dose scanning protocol.

Relapse during surveillance for stage I seminoma occurs most frequently within the first 3 years. ${ }^{9,16,23,38}$ Pooled data from 5 institutions found that in more than 1300 patients, $92 \%$ of recurrences were observed within 3 years. ${ }^{16}$ The systematic review by Martin et al. found the risk of relapse during surveillance is greatest in the first 2 years after orchiectomy with hazard rates of more than $5 \%$ per year. ${ }^{38}$ In years $2-3$, annual hazard rates fall to 1 $5 \%$, then after 4 years to $0.3-1 \%$, and after 10 years are even lower at less than $0.3 \%$ per annum. At the Princess Margaret Cancer Centre, all pelvic relapses during surveillance have occurred within 3 years of orchiectomy. ${ }^{39}$ We perform 6-monthly CTs of the abdomen and pelvis for the first 3 years, followed by CTs limited to the abdomen every 1-2 years thereafter.

The followup schedule intensity is adapted to the greatest risk of recurrence, balanced by the risk of cumulative radiation exposure. The timing of CT scans in our surveillance protocol is similar to the more frequent imaging arm in the MRC TE24 TRISST followup trial randomizing patients to one of four surveillance arms (6-monthly for 2 years, then annually until year 5). ${ }^{40}$ The endpoint of TRISST was to measure the proportion relapsing with stage IIC or higher disease. The trial closed to accrual in 2014, and the results are awaited.

\section{Chest X-ray (CXR)}

In patients on surveillance, thoracic recurrence is low with no studies reporting the mediastinum or lung as an initial site of relapse in isolation. In a retrospective study of more than 1300 patients with stage I seminoma, no recurrences were identified by CXR. ${ }^{16}$ In our cohort of patients on surveillance, only 2 relapses (2\%) were to supradiaphragmatic sites, and both were associated with either para-aortic or inguinal nodal metastases. ${ }^{23,41}$

Despite the low rates of isolated supradiaphragmatic relapses, chest imaging with CT or Xray is described in many followup protocols, ${ }^{10,11,13}$ although the NCCN guidelines reserve chest imaging for patients with thoracic symptoms. ${ }^{12}$ At the Princess Margaret Cancer Centre, we have eliminated chest imaging from our surveillance protocol. 


\section{Serum tumor markers}

There is no evidence to support the clinical utility of monitoring serum tumor markers (STMs) during followup of pure seminoma, even in the setting of elevated levels preorchiectomy. However, STMs are often included in followup protocols for testicular seminoma, ${ }^{11,13}$ despite less than $15 \%$ of pure seminoma producing beta-human chorionic gonadotropin (HCG), and alpha-fetoprotein (AFP) limited to non-seminomatous or mixed tumors. With modern histopathological techniques, seminoma diagnosis is more accurate, and it is rare to relapse with non-seminomatous disease. ${ }^{14}$ Lactate dehydrogenase is a less specific marker compared to AFP and HCG, and has limited sensitivity, specificity and positive predictive value in detecting relapse of testicular germ cell tumors. ${ }^{42}$

Clinical practice guidelines from ASCO advocate for monitoring marker levels to ensure normalization post-orchiectomy, but recommend against routine STM levels in posttreatment surveillance of stage I seminoma. ${ }^{43}$ The pooled multi-institutional data reported an elevated HCG in $3 \%$ of relapses, ${ }^{16}$ and a large Danish surveillance program described isolated elevated STMs in less than $1 \%$ of relapses. ${ }^{9}$ In our series, abnormal STM levels were noted in $14 \%$ of relapsed cases during surveillance, but none in isolation with all patients having radiological evidence of relapsed disease. ${ }^{23,44}$

Although STMs are a minimally invasive investigation, given its low yield of detecting relapse when routine imaging is performed during followup, at our institution we no longer routinely measure STMs during followup of stage I seminoma.

\section{Duration of followup}

The optimal duration of followup for men with testicular seminoma is unknown and often based on consensus opinion. The systematic review by Martin et al. found the risk of recurrence was highest in the first 2 years, then decreased thereafter independent of treatment, with annual hazard rates of less than $1 \%$ after 4 years. ${ }^{38}$ We acknowledge that followup can be discontinued at 5 years as described by other guidelines. ${ }^{11-13}$ However, at the Princess Margaret Cancer Centre we continue to follow patients to 9 years, as $8 \%$ of our relapsed cases have occurred after 5 years, ${ }^{23}$ and we are able to minimize radiation exposure by utilizing low-dose CT imaging limited to the abdomen only. All late relapses in our series were cured with salvage therapy. ${ }^{23}$

Late relapse beyond 10 years has been described, ${ }^{9,23,45}$ but it is uncommon, and there would be little benefit in extending followup to identify this small percentage of patients. ${ }^{16}$ At the last clinic visit prior to discharge, patients and their primary care provider should be advised of the risk of late relapse, and the need to represent if they develop concerning symptoms or signs, but no further surveillance imaging is required after discharge.

\section{Adjuvant therapy}

The reported risk of relapse after adjuvant therapy for stage 1 seminoma is less than $5 \%$, ${ }^{20,46}$ and thus followup intensity may be less than surveillance. In the MRC combined analysis of the TE10, TE18 and TE19 trials for stage I seminoma, the risk of recurrence more than 3 years after adjuvant therapy with either radiotherapy or carboplatin chemotherapy was very low, with only 4 cases of recurrence $(0.2 \%)$ beyond 3 years. ${ }^{47}$ A recent retrospective study 
by Fischer et al. found 15\% of the 185 relapses following adjuvant carboplatin occurred after 3 years. ${ }^{48}$ Sites of relapse vary depending on treatment modality and technique as described below.

\section{Adjuvant radiotherapy}

At the Princess Margaret Cancer Centre we rarely use adjuvant radiotherapy for stage I seminoma, ${ }^{49}$ but followup is similar to that described after definitive radiation treatment for stage II seminoma because of the similar patterns of relapse (Table 2). Our protocol includes regular CXR, but abdominal imaging is omitted due to high rates of retroperitoneal disease control.

In-field recurrences following para-aortic field radiation are rare, and the commonest sites of relapse are to the pelvis and supradiaphragmatic sites. ${ }^{47,50-55}$ In the MRC TE10 trial, the two in-field recurrences occurred in conjunction with pelvic or mediastinal recurrence. ${ }^{55}$ The combined analysis found that in those men receiving adjuvant para-aortic field, $37 \%$ of the 54 relapses were to the pelvis, $26 \%$ to the mediastinum or neck, and $7 \%$ to the abdomen alone. ${ }^{47}$

Patients who received adjuvant dog-leg field radiotherapy in the MRC TE10 trial, had supradiaphragmatic but no abdominopelvic relapses. ${ }^{55}$ The combined MRC analysis reported 17 relapses after adjuvant dog-leg radiotherapy. Supradiaphragmatic sites accounted for $65 \%$ of cases, with isolated pelvic or isolated abdominal relapses each accounting for $6 \% .{ }^{47}$ In our series of men with stage I seminoma treated with adjuvant radiotherapy using a dog-leg technique, relapse to supradiaphragmatic sites was also most common, followed by the inguinal region, and no abdominopelvic relapses were noted. ${ }^{23}$

We therefore recommend that pelvic CT imaging should be performed routinely after adjuvant para-aortic radiotherapy, but not after dog-leg field radiotherapy. We suggest pelvic CTs be performed during the period of highest risk of relapse, that is every 6 months for the first 3 years. Although the risk of relapse to the chest after adjuvant radiotherapy would not be expected to be higher than surveillance, as the mediastinum is one of the first sites of disease recurrence and can be detected on chest imaging before growing to a size large enough to cause symptoms, following adjuvant radiotherapy we recommend regular CXR as outlined in Table 2.

\section{Adjuvant chemotherapy}

Adjuvant single agent carboplatin chemotherapy is an alternative treatment to radiotherapy if surveillance is not pursued, as single agent carboplatin results in 5.3\% relapse at 5 years compared to $4.0 \%$, as seen in the MRC TE19 randomized trial. ${ }^{56}$

The literature guiding followup after carboplatin is sparse. Based on the similar pattern of relapse to the retroperitoneum as for surveillance, ${ }^{32,48,56-61}$ following adjuvant carboplatin we recommend 6-monthly abdominal imaging for the first 3 years. Of the 27 relapses reported in the MRC TE19 trial, 67\% were to the retroperitoneum, 3\% to the supradiaphragmatic site and there were no cases of isolated pelvic relapse. ${ }^{58}$ A retrospective study of 517 patients treated with single-dose adjuvant carboplatin for stage I disease reported $80 \%$ of relapses occurred within 3 years, with $90 \%$ of cases relapsing in the 
retroperitoneum. ${ }^{57}$ Of the 21 relapses in that series, two mediastinal recurrences were reported but both occurred with synchronous retroperitoneal disease. We do not recommend regular CXR following adjuvant carboplatin based on the very low rates of isolated chest relapse. The overall risk of relapse after carboplatin appears to be higher when using 1 course compared to 2, and with carboplatin doses of less than $7 \mathrm{x}$ area under the curve (AUC 7). ${ }^{20}$, 56, 59, 61 In general, as relapse rates after adjuvant therapy are lower than that for surveillance, consideration should be given to less frequent imaging, as well as imaging the abdomen only based on the low risk of isolated pelvic relapse, to minimize radiation exposure.

\section{Stage II seminoma}

At the Princess Margaret Cancer Centre, all patients who present with stage II seminoma are discussed by a multidisciplinary team of urologists, radiation and medical oncologists. We define "bulky" retroperitoneal disease as a single retroperitoneal node measuring more than $4 \mathrm{~cm}$, or multiple enlarged retroperitoneal lymph nodes with the largest node at least $3 \mathrm{~cm}$ in size. ${ }^{62}$ Our practice is for those patients with stage IIA and low-bulk stage IIB disease to be treated with definitive radiotherapy to the para-aortic and ipsilateral pelvic lymph nodes using a modified dog-leg technique, ${ }^{4}$ if the disease can safely be encompassed in the radiation treatment volume, with no contraindications to radiotherapy and no concerns about aberrant lymphatic drainage due to prior scrotal surgery. For all other patients with stage II disease, platinum-based chemotherapy with three cycles of bleomycin-etoposide-cisplatin (BEP), or four cycles of etoposide-cisplatin (EP) if there is a contraindication to bleomycin, is recommended. ${ }^{63}$ Platinum-based chemotherapy is also recommended for patients with stage IIC or bulky stage IIB disease because of the high risk of distant disease associated with tumor volume. The rates of relapse after radiation treatment for bulky retroperitoneal disease are significantly higher compared to treatment with cisplatin-based chemotherapy. ${ }^{3} \mathrm{We}$ utilize the same treatment approach for patients who develop retroperitoneal relapse whilst on surveillance, and the same followup regimen depending on treatment modality.

\section{Definitive radiotherapy}

Radiotherapy for stage IIA and IIB disease is an effective treatment resulting in relapse-free survival rates of more than $80 \%$. ${ }^{3,4,64}$ Upon completion of radiotherapy, we perform a CT abdomen and pelvis at 3 months, then every 3-6 months until a complete radiological response with normalization of imaging is observed. Because of the reported high rates of infield disease control and pattern of relapse to supradiaphragmatic sites, ${ }^{3,4,8,65,66}$ we do not routinely perform further abdominal imaging after radiological response is documented. Based on patterns of failure, our followup protocol includes chest imaging, and given the high doses of radiation associated with chest CTs, we recommend CXRs at 6-monthly intervals for the first 3 years, then annually until year 5 , with biennial imaging until year 9 (Table 2). Similar to our surveillance program, at each clinic visit a history and physical examination is performed, and serum hormone levels are measured.

One of the larger studies of definitive radiotherapy for stage IIA and IIB seminoma treated 94 patients with a modified dog-leg field and reported 4 cases of relapse within 40 months, including 3 mediastinal relapses and 1 recurrence at the field edge. ${ }^{4}$ The Mayo 
Clinic's series of 52 patients found in-field relapses to be uncommon, with only 1 para-aortic relapse in a man with stage IIC disease who relapsed within 6 months, suggesting that bulky disease may not respond to radiation alone. ${ }^{8}$ The majority of relapses were to supradiaphragmatic sites such as the mediastinum, supraclavicular fossa, and lung, and occurred within 2 years of treatment. Other small series of patients receiving definitive radiotherapy for stage II seminoma have reported similar patterns of relapse to supradiaphragmatic sites, with in-field relapses rare. ${ }^{64-66}$

Our report of 49 men with stage IIA seminoma treated with radiotherapy to the paraaortic nodes and pelvis found none of the 4 relapses were in the radiation volume; of the 30 men with stage IIB seminoma who received abdominopelvic radiotherapy, 3 experienced disease relapse including 2 cases of relapse to the left supraclavicular nodes $+/$ left axilla, and 1 case of paraaortic relapse. ${ }^{3}$ The commonest time to relapse was in the first two years after treatment, with all relapses occurring by 4 years. Other studies of radiotherapy for stage II seminoma describe relapses up to 6 years from treatment. ${ }^{4,32,64,65}$ Similar to our stage I surveillance program, we continue to follow patients to 9 years.

\section{Definitive chemotherapy}

For stage II seminoma, cisplatin-based chemotherapy is typically reserved for bulky disease but may be considered for low volume disease if there are contraindications to radiation treatment.

The evidence for followup after chemotherapy for stage II seminoma is limited, with many studies including both seminoma and non-seminoma, as well as patients with more advanced disease. ${ }^{67-71}$ It is thus difficult to make recommendations for followup in this rare group of patients and we advise that these cases should be managed at expert centres with an individualized treatment and followup approach.

In general, as with stage II seminoma treated with radiotherapy, followup abdominal imaging is required to ensure disease regression after chemotherapy. Disease resolution can take many months to years, and tumors that demonstrate ongoing shrinkage can often be observed with close followup. In some cases residual fibrotic lesions may remain, particularly in men with large volume disease prior to treatment. Fluorodeoxyglucose positron emission tomography (FDG-PET) may be useful to determine the presence of active residual disease. ${ }^{72}$ Residual masses that do not demonstrate regression post-chemotherapy or that remain PET-avid on serial imaging more than 6 weeks apart, should be referred to an expert centre. Treatment of suspected residual disease includes surgical resection or second line chemotherapy. ${ }^{12,70,73,74}$

Once there is no evidence of active disease, our followup protocol for advanced seminoma is the same as that for non-seminomatous germ cell tumors treated with chemotherapy (Table 3). Patients may be at risk of both local and distant relapse most commonly within 2 years of treatment, ${ }^{3,32}$ and imaging includes 6-monthly CT scans of the chest, abdomen and pelvis for the first 2 years, then at 5 and 9 years.

As elevated STMs may be one of the first signs of relapse in initial advanced disease, the ASCO guidelines recommend regular monitoring of STMs during followup, and we also measure STMs after chemotherapy for advanced seminoma. ${ }^{43}$ 


\section{Conclusion}

Our followup recommendations have been modelled on the timing and patterns of relapse for early stage testicular seminoma based on the existing literature, our institution's experience and opinion of our centre's expert oncologists.

Limitations of our guidelines include basing our recommendations, particularly for stage II seminoma, on single-institution reports due to the lack of randomized evidence. Other limitations include the variations in treatment technique including chemotherapy and radiotherapy doses, and radiotherapy fields in reported studies, variability in imaging and followup regimens that may affect relapse detection, and in the case of adjuvant carboplatin for stage I disease, the lack of long-term data to guide followup protocols.

The followup program described has been implemented at the the Princess Margaret Cancer Centre, and may serve as a framework for other institutions that manage testicular seminoma. 


\section{References}

1. Ghazarian AA, Trabert B, Devesa SS, McGlynn KA. Recent trends in the incidence of testicular germ cell tumors in the United States. Andrology. 2015;3: 13-18.

2. Vallis KA, Howard GC, Duncan W, Cornbleet MA, Kerr GR. Radiotherapy for stages I and II testicular seminoma: results and morbidity in 238 patients. British Journal of Radiology. 1995;68: 400-405.

3. Chung PW, Gospodarowicz MK, Panzarella T, et al. Stage II testicular seminoma: patterns of recurrence and outcome of treatment. European Urology. 2004;45: 754-759; discussion 759-760.

4. Classen J, Schmidberger H, Meisner C, et al. Radiotherapy for stages IIA/B testicular seminoma: final report of a prospective multicenter clinical trial. Journal of Clinical Oncology. 2003;21: 1101-1106.

5. Paly JJ, Lin CC, Gray PJ, et al. Management and outcomes of clinical stage IIA/B seminoma: Results from the National Cancer Data Base 1998-2012. Pract Radiat Oncol. 2016.

6. Glaser SM, Vargo JA, Balasubramani GK, Beriwal S. Surveillance and Radiation Therapy for Stage I Seminoma--Have We Learned From the Evidence? Int J Radiat Oncol Biol Phys. 2016;94: 75-84.

7. Giannatempo P, Greco T, Mariani L, et al. Radiotherapy or chemotherapy for clinical stage IIA and IIB seminoma: a systematic review and meta-analysis of patient outcomes. Annals of Oncology. 2015;26: 657-668.

8. Hallemeier CL, Pisansky TM, Davis BJ, Choo R. Long-term outcomes of radiotherapy for stage II testicular seminoma--the Mayo Clinic experience. Urologic Oncology. 2013;31: 1832-1838.

9. Mortensen MS, Lauritsen J, Gundgaard MG, et al. A nationwide cohort study of stage I seminoma patients followed on a surveillance program. European Urology. 2014;66: 11721178.

10. Cathomas R, Helbling D, Stenner F, et al. Interdisciplinary evidence-based recommendations for the followup of testicular cancer patients: a joint effort. Swiss Med Wkly. 2010;140: 356-369.

11. van As NJ, Gilbert DC, Money-Kyrle J, et al. Evidence-based pragmatic guidelines for the followup of testicular cancer: optimising the detection of relapse. British Journal of Cancer. 2008;98: 1894-1902.

12. Motzer RJ, Jonasch E, Agarwal N, et al. NCCN clinical practice guidelines in oncology; testicular cancer. Available from

URL: http://www.nccn.org/professionals/physician_gls/pdf/testicular.pdf [accessed 31 October, 2016].

13. Albers P, Albrecht W, Algaba F, et al. Guidelines on testicular cancer. Available from URL: www.uroweb.org/wp-content/uploads/11-Testicular-Canccer_LR1.pdf [accessed 31 October, 2016]. 
14. Oldenburg J, Fossa SD, Nuver J, et al. Testicular seminoma and non-seminoma: ESMO Clinical Practice Guidelines for diagnosis, treatment and followup. Annals of Oncology. 2013;24 Suppl 6: vi125-132.

15. Tyldesley S, Voduc D, McKenzie M, Duncan G, Liu M, Wu D. Surveillance of stage I testicular seminoma: British Columbia Cancer Agency Experience 1992 to 2002. Urology. 2006;67: 594-598.

16. Kollmannsberger C, Tandstad T, Bedard PL, et al. Patterns of relapse in patients with clinical stage I testicular cancer managed with active surveillance. Journal of Clinical Oncology. 2015;33: 51-57.

17. Cummins S, Yau T, Huddart R, Dearnaley D, Horwich A. Surveillance in stage I seminoma patients: a long-term assessment. European Urology. 2010;57: 673-678.

18. Warde P, Specht L, Horwich A, et al. Prognostic factors for relapse in stage I seminoma managed by surveillance: a pooled analysis. Journal of Clinical Oncology. 2002;20: 44484452.

19. Tandstad T, Stahl O, Dahl O, et al. Treatment of stage I seminoma, with one course of adjuvant carboplatin or surveillance, risk-adapted recommendations implementing patient autonomy: a report from the Swedish and Norwegian Testicular Cancer Group (SWENOTECA). Annals of Oncology. 2016;27: 1299-1304.

20. Dieckmann KP, Dralle-Filiz I, Matthies C, et al. Testicular seminoma clinical stage 1: treatment outcome on a routine care level. Journal of Cancer Research \& Clinical Oncology. 2016;142: 1599-1607.

21. Jones G, Arthurs B, Kaya $\mathrm{H}$, et al. Overall survival analysis of adjuvant radiation versus observation in stage I testicular seminoma: a surveillance, epidemiology, and end results (SEER) analysis. American Journal of Clinical Oncology. 2013;36: 500-504.

22. Choo R, Thomas G, Woo T, et al. Long-term outcome of postorchiectomy surveillance for Stage I testicular seminoma. Int J Radiat Oncol Biol Phys. 2005;61: 736-740.

23. Hosni A, Warde P, Jewett M, et al. Clinical Characteristics and Outcomes of Late Relapse in Stage I Testicular Seminoma. Clinical Oncology (Royal College of Radiologists). 2016.

24. Andreassen KE, Grotmol T, Cvancarova MS, Johannesen TB, Fossa SD. Risk of metachronous contralateral testicular germ cell tumors: a population-based study of 7,102 Norwegian patients (1953-2007). Int J Cancer. 2011;129: 2867-2874.

25. Fossa SD, Chen J, Schonfeld SJ, et al. Risk of contralateral testicular cancer: a population-based study of 29,515 U.S. men. Journal of the National Cancer Institute. 2005;97: 1056-1066.

26. Sprauten M, Brydoy M, Haugnes HS, et al. Longitudinal serum testosterone, luteinizing hormone, and follicle-stimulating hormone levels in a population-based sample of long-term testicular cancer survivors. Journal of Clinical Oncology. 2014;32: 571-578.

27. Morales A, Bebb RA, Manjoo P, et al. Diagnosis and management of testosterone deficiency syndrome in men: clinical practice guideline. CMAJ. 2015;187: 1369-1377.

28. Andersen BL, DeRubeis RJ, Berman BS, et al. Screening, assessment, and care of anxiety and depressive symptoms in adults with cancer: an American Society of Clinical Oncology guideline adaptation. Journal of Clinical Oncology. 2014;32: 1605-1619. 
29. Howell D, Keshavarz H, Esplen MJ, et al. A Pan Canadian Practice Guideline: Screening, Assessment and Care of Psychosocial Distress, Depression, and Anxiety in Adults with Cancer, Toronto: Canadian Partnership Against Cancer and the Canadian Association of Psychosocial Oncology July 2015.

30. Dahl AA, Haaland CF, Mykletun A, et al. Study of anxiety disorder and depression in long-term survivors of testicular cancer. Journal of Clinical Oncology. 2005;23: 2389-2395.

31. Beard CJ, Travis LB, Chen MH, et al. Outcomes in stage I testicular seminoma: a population-based study of 9193 patients. Cancer. 2013;119: 2771-2777.

32. Tandstad T, Smaaland R, Solberg A, et al. Management of seminomatous testicular cancer: a binational prospective population-based study from the Swedish norwegian testicular cancer study group. Journal of Clinical Oncology. 2011;29: 719-725.

33. Lin EC. Radiation risk from medical imaging. Mayo Clinic Proceedings. 2010;85: 11421146.

34. Mettler FA, Jr., Huda W, Yoshizumi TT, Mahesh M. Effective doses in radiology and diagnostic nuclear medicine: a catalog. Radiology. 2008;248: 254-263.

35. National Research Council Committee to Assess Health Risks from Exposure to Low Levels of Ionizing Radiation. Health risks from exposure to low levels of ionizing radiation: BEIR VII, Phase 2. Washington, DC: National Academies Press, 2006.

36. Murphy KP, Crush L, O'Neill SB, et al. Feasibility of low-dose CT with model-based iterative image reconstruction in followup of patients with testicular cancer. Eur $\mathrm{J}$ Radiol Open. 2016;3: 38-45.

37. O'Malley ME, Chung P, Haider M, et al. Comparison of low dose with standard dose abdominal/pelvic multidetector CT in patients with stage 1 testicular cancer under surveillance. European Radiology. 2010;20: 1624-1630.

38. Martin JM, Panzarella T, Zwahlen DR, Chung P, Warde P. Evidence-based guidelines for following stage 1 seminoma. Cancer. 2007;109: 2248-2256.

39. McPartlin A, Hosni A, Bedard PL, et al. Optimization of an imaging protocol for stage I seminoma surveillance based on variations in relapse location over time. Journal of Clinical Oncology. 2016;34.

40. Cafferty FH, Gabe R, Huddart RA, et al. UK management practices in stage I seminoma and the Medical Research Council Trial of Imaging and Schedule in Seminoma Testis managed with surveillance. Clinical Oncology (Royal College of Radiologists). 2012;24: 2529.

41. Tolan S, Vesprini D, Jewett MA, et al. No role for routine chest radiography in stage I seminoma surveillance. European Urology. 2010;57: 474-479.

42. Venkitaraman R, Johnson B, Huddart RA, Parker CC, Horwich A, Dearnaley DP. The utility of lactate dehydrogenase in the followup of testicular germ cell tumours. BJU Int. 2007;100: 30-32.

43. Gilligan TD, Hayes DF, Seidenfeld J, Temin S. ASCO Clinical Practice Guideline on Uses of Serum Tumor Markers in Adult Males With Germ Cell Tumors. J Oncol Pract. 2010;6: 199-202. 
44. Vesprini D, Chung P, Tolan S, et al. Utility of serum tumor markers during surveillance for stage I seminoma. Cancer. 2012;118: 5245-5250.

45. Blanke CD, Delgalvis SC, Nichols GR. Late recurrence of seminoma. Southern Medical Journal. 1997;90: 653-655.

46. Wood L, Kollmannsberger C, Jewett M, et al. Canadian consensus guidelines for the management of testicular germ cell cancer. Can Urol Assoc J. 2010;4: e19-38.

47. Mead GM, Fossa SD, Oliver RT, et al. Randomized trials in 2466 patients with stage I seminoma: patterns of relapse and followup. Journal of the National Cancer Institute. 2011;103: 241-249.

48. Fischer S, Tandstad T, Wheater M, et al. Outcome of Men With Relapse After Adjuvant Carboplatin for Clinical Stage I Seminoma. Journal of Clinical Oncology. 2017;35: 194-200. 49. Leung $\mathrm{E}$, Warde $\mathrm{P}$, Jewett $\mathrm{M}$, et al. Treatment burden in stage I seminoma: a comparison of surveillance and adjuvant radiation therapy. BJU Int. 2013;112: 1088-1095.

50. Clasen J, Schmidberger H, Souchon R, et al. What is the value of routine followup in stage I seminoma after paraaortic radiotherapy?: an analysis of the German Testicular Cancer Study Group (GTCSG) in 675 prospectively followed patients. Strahlentherapie und Onkologie. 2009;185: 349-354.

51. Classen J, Schmidberger H, Meisner C, et al. Para-aortic irradiation for stage I testicular seminoma: results of a prospective study in 675 patients. A trial of the German testicular cancer study group (GTCSG). British Journal of Cancer. 2004;90: 2305-2311.

52. Hallemeier CL, Choo R, Davis BJ, Leibovich BC, Costello BA, Pisansky TM. Excellent long-term disease control with modern radiotherapy techniques for stage I testicular seminoma--the Mayo Clinic experience. Urol Oncol. 2014;32: 24 e21-26.

53. Logue JP, Harris MA, Livsey JE, Swindell R, Mobarek N, Read G. Short course paraaortic radiation for stage I seminoma of the testis. Int J Radiat Oncol Biol Phys. 2003;57: 1304-1309.

54. Livsey JE, Taylor B, Mobarek N, Cooper RA, Carrington B, Logue JP. Patterns of relapse following radiotherapy for stage I seminoma of the testis: implications for followup. Clinical Oncology (Royal College of Radiologists). 2001;13: 296-300.

55. Fossa SD, Horwich A, Russell JM, et al. Optimal planning target volume for stage I testicular seminoma: A Medical Research Council randomized trial. Medical Research Council Testicular Tumor Working Group. Journal of Clinical Oncology. 1999;17: 1146. 56. Oliver RT, Mead GM, Rustin GJ, et al. Randomized trial of carboplatin versus radiotherapy for stage I seminoma: mature results on relapse and contralateral testis cancer rates in MRC TE19/EORTC 30982 study (ISRCTN27163214). Journal of Clinical Oncology. 2011;29: 957-962.

57. Chau C, Cathomas R, Wheater M, et al. Treatment outcome and patterns of relapse following adjuvant carboplatin for stage I testicular seminomatous germ-cell tumour: results from a 17-year UK experience. Annals of Oncology. 2015;26: 1865-1870.

58. Oliver RT, Mason MD, Mead GM, et al. Radiotherapy versus single-dose carboplatin in adjuvant treatment of stage I seminoma: a randomised trial. Lancet. 2005;366: 293-300. 
59. Dieckmann KP, Bruggeboes B, Pichlmeier U, Kuster J, Mullerleile U, Bartels H. Adjuvant treatment of clinical stage I seminoma: is a single course of carboplatin sufficient? Urology. 2000;55: 102-106.

60. Aparicio J, Germa JR, Garcia del Muro X, et al. Risk-adapted management for patients with clinical stage I seminoma: the Second Spanish Germ Cell Cancer Cooperative Group study. Journal of Clinical Oncology. 2005;23: 8717-8723.

61. Steiner H, Scheiber K, Berger AP, et al. Retrospective multicentre study of carboplatin monotherapy for clinical stage I seminoma. BJU Int. 2011;107: 1074-1079.

62. Sridharan S, Chung PWM, Jewett MA, et al. Use of radiotherapy for seminoma patients with low-volume infradiaphragmatic nodal disease. Journal of Clinical Oncology. 2013;31: 335-335.

63. Feldman DR, Bosl GJ. Treatment of stage I seminoma: is it time to change your practice? J Hematol Oncol. 2008;1: 22.

64. Zagars GK, Pollack A. Radiotherapy for stage II testicular seminoma. Int J Radiat Oncol Biol Phys. 2001;51: 643-649.

65. Patterson H, Norman AR, Mitra SS, et al. Combination carboplatin and radiotherapy in the management of stage II testicular seminoma: comparison with radiotherapy treatment alone. Radiotherapy \& Oncology. 2001;59: 5-11.

66. Bayens YC, Helle PA, Van Putten WL, Mali SP. Orchidectomy followed by radiotherapy in 176 stage I and II testicular seminoma patients: benefits of a 10-year followup study. Radiotherapy \& Oncology. 1992;25: 97-102.

67. Gholam D, Fizazi K, Terrier-Lacombe MJ, Jan P, Culine S, Theodore C. Advanced seminoma--treatment results and prognostic factors for survival after first-line, cisplatinbased chemotherapy and for patients with recurrent disease: a single-institution experience in 145 patients. Cancer. 2003;98: 745-752.

68. Fossa SD, Oliver RT, Stenning SP, et al. Prognostic factors for patients with advanced seminoma treated with platinum-based chemotherapy. European Journal of Cancer. 1997;33: 1380-1387.

69. Fossa SD, Borge L, Aass N, Johannessen NB, Stenwig AE, Kaalhus O. The treatment of advanced metastatic seminoma: experience in 55 cases. Journal of Clinical Oncology. 1987;5: 1071-1077.

70. Puc HS, Heelan R, Mazumdar M, et al. Management of residual mass in advanced seminoma: results and recommendations from the Memorial Sloan-Kettering Cancer Center. Journal of Clinical Oncology. 1996;14: 454-460.

71. Horwich A, Paluchowska B, Norman A, et al. Residual mass following chemotherapy of seminoma. Annals of Oncology. 1997;8: 37-40.

72. De Santis M, Becherer A, Bokemeyer C, et al. 2-18fluoro-deoxy-D-glucose positron emission tomography is a reliable predictor for viable tumor in postchemotherapy seminoma: an update of the prospective multicentric SEMPET trial. Journal of Clinical Oncology. 2004;22: 1034-1039.

73. Herr HW, Sheinfeld J, Puc HS, et al. Surgery for a post-chemotherapy residual mass in seminoma. Journal of Urology. 1997;157: 860-862. 
74. Warde P, Huddart R, Bolton D, Heidenreich A, Gilligan T, Fossa S. Management of localized seminoma, stage I-II: SIU/ICUD Consensus Meeting on Germ Cell Tumors (GCT), Shanghai 2009. Urology. 2011;78: S435-443. 


\begin{tabular}{|c|c|c|c|c|c|c|c|c|c|c|c|c|}
\hline \multirow{2}{*}{$\begin{array}{l}\text { Time post- } \\
\text { orchiectomy }\end{array}$} & \multicolumn{12}{|c|}{ Month } \\
\hline & 1 & 2 & 3 & 4 & 5 & 6 & 7 & 8 & 9 & 10 & 11 & 12 \\
\hline Year 1 & & & & & & $\begin{array}{c}\text { H\&P } \\
\text { CT } \\
\text { abdomen } \\
\text { \& pelvis }\end{array}$ & & & & & & $\begin{array}{c}\text { H\&P } \\
\text { CT } \\
\text { abdomen } \\
\text { \& pelvis } \\
\text { Hormone } \\
\text { levels }\end{array}$ \\
\hline Year 2 & & & & & & $\begin{array}{c}\text { H\&P } \\
\text { CT } \\
\text { abdomen } \\
\text { \& pelvis }\end{array}$ & & & & & & $\begin{array}{c}\text { H\&P } \\
\text { CT } \\
\text { abdomen } \\
\text { \& pelvis } \\
\text { Hormone } \\
\text { levels }^{*}\end{array}$ \\
\hline Year 3 & & & & & & $\begin{array}{c}\text { H\&P } \\
\text { CT } \\
\text { abdomen } \\
\text { \& pelvis }\end{array}$ & & & & & & $\begin{array}{c}\text { H\&P } \\
\text { CT } \\
\text { abdomen } \\
\text { \& pelvis } \\
\text { Hormone } \\
\text { levels }\end{array}$ \\
\hline Year 4 & & & & & & & & & & & & $\begin{array}{c}\text { H\&P } \\
\text { CT } \\
\text { abdomen } \\
\text { Hormone } \\
\text { levels }\end{array}$ \\
\hline Year 5 & & & & & & & & & & & & $\begin{array}{c}\text { H\&P } \\
\text { CT } \\
\text { abdomen } \\
\text { Hormone } \\
\text { levels }\end{array}$ \\
\hline Year 7 & & & & & & & & & & & & $\begin{array}{c}\text { H\&P } \\
\text { CT } \\
\text { abdomen } \\
\text { Hormone } \\
\text { levels }\end{array}$ \\
\hline Year 9 & & & & & & & & & & & & $\begin{array}{c}\text { H\&P } \\
\text { CT } \\
\text { abdomen } \\
\text { Hormone } \\
\text { levels }\end{array}$ \\
\hline
\end{tabular}

*Total testosterone, luteinizing hormone (LH), follicle-stimulating hormone (FSH). CT: lowdose computed tomography; H\&P: history and physical examination. 


\begin{tabular}{|c|c|c|c|c|c|c|c|c|c|c|c|c|}
\hline \multirow{2}{*}{$\begin{array}{l}\text { Time post- } \\
\text { orchiectomy }\end{array}$} & \multicolumn{12}{|c|}{ Month } \\
\hline & 1 & 2 & 3 & 4 & 5 & 6 & 7 & 8 & 9 & 10 & 11 & 12 \\
\hline Year 1 & & & & & & $\begin{array}{l}\text { H\&P } \\
\text { CXR }\end{array}$ & & & & & & $\begin{array}{c}\text { H\&P } \\
\text { CXR } \\
\text { Hormone levels }\end{array}$ \\
\hline Year 2 & & & & & & $\begin{array}{l}\text { H\&P } \\
\text { CXR }\end{array}$ & & & & & & $\begin{array}{c}\text { H\&P } \\
\text { CXR } \\
\text { Hormone levels }\end{array}$ \\
\hline Year 3 & & & & & & $\begin{array}{l}\text { H\&P } \\
\text { CXR }\end{array}$ & & & & & & $\begin{array}{c}\text { H\&P } \\
\text { CXR } \\
\text { Hormone levels }\end{array}$ \\
\hline Year 4 & & & & & & & & & & & & $\begin{array}{c}\text { H\&P } \\
\text { CXR } \\
\text { Hormone levels }\end{array}$ \\
\hline Year 5 & & & & & & & & & & & & $\begin{array}{c}\text { H\&P } \\
\text { CXR } \\
\text { Hormone levels }\end{array}$ \\
\hline Year 7 & & & & & & & & & & & & $\begin{array}{c}\text { H\&P } \\
\text { CXR } \\
\text { Hormone levels }\end{array}$ \\
\hline Year 9 & & & & & & & & ( & & & & $\begin{array}{c}\text { H\&P } \\
\text { CXR } \\
\text { Hormone levels }\end{array}$ \\
\hline
\end{tabular}

${ }^{*}$ Total testosterone, luteinizing hormone (LH), follicle-stimulating hormone (FSH). CXR: chest X-ray; H\&P: history and physical examination. 


\begin{tabular}{|c|c|c|c|c|c|c|c|c|c|c|c|c|}
\hline \multirow{2}{*}{$\begin{array}{l}\text { Time } \\
\text { post- } \\
\text { orchiec } \\
\text { tomy }\end{array}$} & \multicolumn{12}{|c|}{ Month } \\
\hline & 1 & 2 & 3 & 4 & 5 & 6 & 7 & 8 & 9 & $\begin{array}{l}\mathbf{1} \\
\mathbf{0}\end{array}$ & $\begin{array}{l}1 \\
1\end{array}$ & Month 12 \\
\hline Year 1 & & & $\begin{array}{l}\text { H\&P } \\
\text { STMs }\end{array}$ & & & $\begin{array}{c}\text { H\&P } \\
\text { STMs } \\
\text { CT } \\
\text { chest/abdome } \\
\text { n/pelvis }\end{array}$ & & & $\begin{array}{l}\text { H\&P } \\
\text { STMs }\end{array}$ & & & $\begin{array}{c}\text { H\&P } \\
\text { STMs } \\
\text { CT } \\
\text { chest/abdomen } \\
\text { /pelvis } \\
\text { Hormone } \\
\text { levels } \\
\text { Creatinine }\end{array}$ \\
\hline Year 2 & & & $\begin{array}{l}\text { H\&P } \\
\text { STMs }\end{array}$ & & & $\begin{array}{c}\text { H\&P } \\
\text { STMs } \\
\text { CT } \\
\text { chest/abdome } \\
\text { n/pelvis }\end{array}$ & & & $\begin{array}{l}\text { H\&P } \\
\text { STMs }\end{array}$ & & & $\begin{array}{c}\text { H\&P } \\
\text { STMs } \\
\text { CT } \\
\text { chest/abdomen } \\
\text { /pelvis } \\
\text { Hormone } \\
\text { levels } \\
\text { Creatinine }\end{array}$ \\
\hline Year 3 & & & & $\begin{array}{l}\text { H\&P } \\
\text { STMs }\end{array}$ & & & 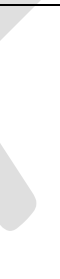 & $\begin{array}{l}\text { H\&P } \\
\text { STMs }\end{array}$ & & & & $\begin{array}{c}\text { H\&P } \\
\text { STMs } \\
\text { Hormone } \\
\text { levels } \\
\text { Creatinine }\end{array}$ \\
\hline Year 4 & & & & & & $\begin{array}{c}\text { H\&P } \\
\text { STMs }\end{array}$ & & & & & & $\begin{array}{c}\text { H\&P } \\
\text { STMs } \\
\text { Hormone } \\
\text { levels } \\
\text { Creatinine }\end{array}$ \\
\hline Year 5 & & & & & & & & & & & & $\begin{array}{c}\text { H\&P } \\
\text { STMs } \\
\text { CT } \\
\text { chest/abdomen } \\
\text { /pelvis } \\
\text { Hormone } \\
\text { levels } \\
\text { Creatinine }\end{array}$ \\
\hline Year 6 & & & & & & & & & & & & $\begin{array}{l}\text { H\&P } \\
\text { STMs }\end{array}$ \\
\hline
\end{tabular}




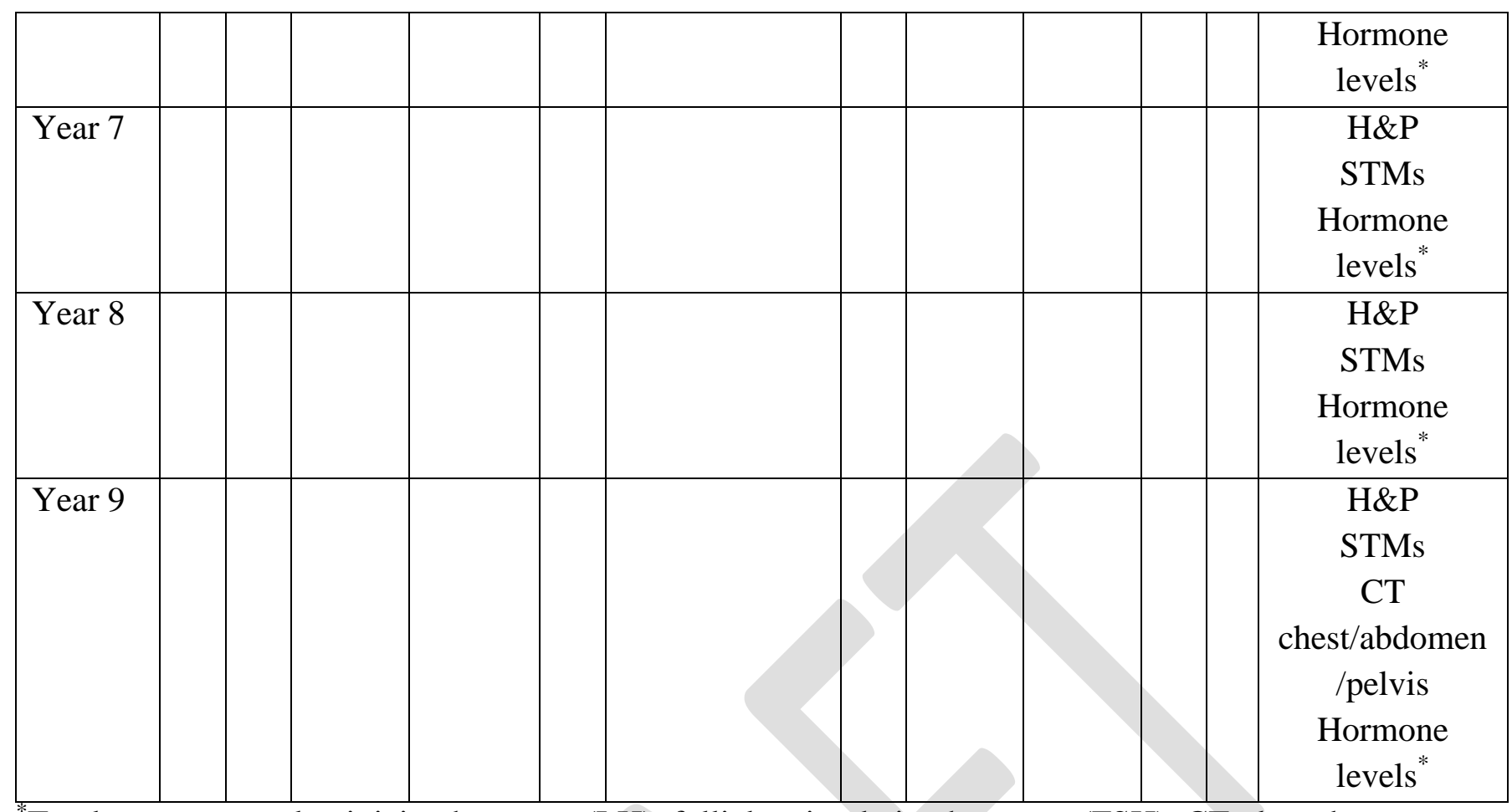

*Total testosterone, luteinizing hormone (LH), follicle-stimulating hormone (FSH). CT: low-dose computed tomography; H\&P: history and physical examination; STMs: serum tumor markers. 